\section{Carbon dioxide fluctuations}

\section{from Peter D. Moore}

THE global movement of carbon between non-living and living matter is one of the many cyclic processes upon which man's industrial activities are having considerable effect. The combustion of fossil fuels accelerates one part of the 'natural' cycling of carbon; it replaces the respiratory activity of decomposer organisms, whose consumptive processes were impaired by anaerobic conditions during the accumulation of the organic detritus which is now coal, oil and gas. Industrial combustion, however, is almost certainly responsible for the observed rise in ambient atmospheric carbon dioxide levels over the past sixteen years in Hawaii. Baxter and Walton (Proc. $R$. Soc., A318, 213; 1970) suggest an increase of $22 \%$ on pre-industrial levels of atmospheric $\mathrm{CO}_{2}$. Evidently the increased output of carbon dioxide, resulting from increasing industrialisation, is not being fully compensated by $\mathrm{CO}_{2}$ consumption in other global reservoirs.

The major potential carbon reservoirs which might be expected to increase consumption of atmospheric $\mathrm{CO}_{2}$ as concentrations rise are the oceans and the living organic matter of the planet. It is obviously a matter of considerable urgency to develop predictive models of this equilibrating system in order to determine the likely outcome of man's industrial activity; several such models now exist (for example, Fairhall, Nature, 245, 20; 1973; Broecker et al. in Impingement of Man on the Oceans, edit. by D. W. Hood; Wiley, 1971). Opinions differ as to the likely influence of the additional carbon load upon the chemistry of ocean water (see Whitfield, Nature, 247, 523; 1974).

World biomass variations are not easily estimated. One might predict increases in photosynthetic production as a consequence of enhanced $\mathrm{CO}_{2}$ levels, but one must set against this the possibilities of reduced productivity because of raised $\mathrm{SO}_{2}$ and $\mathrm{O}_{3}$ concentrations in the atmosphere of industrial countries and also the destruction by man of many naturally productive areas. The production: respiration ratio of the world's biota could be moving in either direction. Reiners (and several other contributors to Brookhaven Symp. Biol., 25; 1973) have drawn attention to the general lack of reliable data and the wide disparity among estimates of such carbon reservoirs as living biomass and detritus pools, let alone transfer rates. Attempts have also been made to use tree growth rings as indices of forest production (for example, Whittaker et al., Ecol. Monogr., 44, 233; 1974) and Farmer and Baxter (Nature, 247, 273; 1974) have used the isotope ratio of ${ }^{14} \mathrm{C} /{ }^{12} \mathrm{C}$ in efforts to identify the contribution of fossil carbon to the growth rings of trees in Britain.

In this issue of Nature (page 136) Hall, Ekdahl and Wartenburg use a method which has been applied in many smaller scale studies to estimate trends in the biotic metabolism of carbon in the Northern Hemisphere. Their idea is based upon the flux study concept as used for the determination of forest respiration by Woodwell and Dykeman (Science, 154, 1031; 1966), but rather than diurnal changes, they use seasonal fluctuation in ambient $\mathrm{CO}_{2}$ levels (values are corrected by subtraction of the estimated residuum of industrially derived $\mathrm{CO}_{2}$ after partition with the oceans). Increasing $\mathrm{CO}_{2}$ levels in autumn and winter provide a measure of the respiration of the hemispheric ecosystem and decreasing levels in spring and summer give a measure of net photosynthesis. Using the data from the Mauna Loa observatory, Hawaii, they calculate hemispheric net production and respiration for the sixteen years over which data are available and they find no significant change during this period. This suggests that either the total biomass of the hemisphere is unchanged, or any loss of productivity due to pollution or changing land use has been compensated by an increase in the productivity of the remainder. It is possible to argue about the best figures to use for industrial carbon output and the equilibration of this carbon with the oceans (the prime considerations in the adjustment of the Mauna Loa data) but the authors claim that the outcome of their calculations is relatively insensitive to possible errors in these data. Their plea for a more extensive worldwide monitoring of atmospheric $\mathrm{CO}_{2}$ fluctuations as an aid, among other things, to the detection of any major variation in global carbon metabolism, should be supported by anyone with a sense of responsibility for the environment.

\section{Statistics and climatic change}

from Michael Kelly

GREAT advances are currently being made in the study of climatic change. This progress is attributable not only to greater academic and, in certain countries, governmental interest in the subject but aiso to the increasing use of powerful statistical tools in the analysis of climatic time series.

Post-glacial climatic change can be viewed as movement between atmospheric circulation states of predominantly strong, westerly airflow (leading to warming of higher latitudes in the sector or sectors affected, as occurred globally in the first half of the twentieth century) and those of predominantly weaker, more meridional airflow (leading to cooling). Characteristic time scales or periodicities can often be attached to variations in climate; this had led to many attempts to explain the observed persistence of a particular circulation state for periods of months to centuries and also the change to a different state at fairly regular intervals. Climatic cycles may eventually prove of great value in climatic forecasting but until a physical reason for their continued existence is established, such forecasts can only be tentative.

The search for the causes of climatic change and climatic cycles is proceeding on two fronts: computer modelling of the atmospheric circulation and statistical analysis of climatic data. The potential of both of these approaches is great but, at present, most computer models are too coarse to differentiate between different circulation states experienced during the last millennia and it is the second, more traditional, approach to the study of climatic change that has been greatly improved by the availability of new statistical methods and that is rapidly increasing understanding of climatic change.

A recent paper by Trenberth $(Q . J l$ $R$. met. Soc., 101, 55; 1975) illustrates the use of sophisticated data analysis in a study of ocean-atmosphere interaction in the region of New Zealand and Australia. Empirical orthogonal function analysis was used to identify the major sea level pressure (SLP) anomaly patterns, that is, atmospheric circulation states, and the major sea surface temperature (SST) anomaly patterns for the period 1959-1972. Spectral and cross-spectral analysis of time series of the pattern coefficients then revealed relationships, both current and lag, between the SLP and SST anomaly patterns, associated with a quasi-biennial periodicity which has been observed in many climatic parameters. These relationships enabled Trenberth to construct a sequence of SLP and SST anomaly charts for the two-year cycle, which showed that the SST anomalies were largely caused by oceanic advection resulting from the wind drag associated with the different SLP patterns.

This research did not indicate that feedback from ocean to atmosphere was of great importance in the region studied. But work in other areas, particularly the Pacific and North Atlantic, has shown that anomalous sea temperature patterns often reinforce the atmosphere circulation states that produce them. Although this positive feedback can explain the persistence of certain atmospheric circulation states, 